KATHE BISCHOFF

DIE WINKLERKUR 



\title{
DIE WINKLERKUR
}

\author{
Ein Weg zur Heilung \\ durch Beeinflussung der Organismuszentrale \\ von \\ Dr. med. KATHE BISCHOFF
}

2. völlig neubearbeitete Auflage

$\begin{array}{llll}1 & 9 & 6 & 7\end{array}$

A. MARCUS \& E. WEBER'S VERLAG - BERLIN 30 


\section{(C)}

Copyright 1967 by A. Marcus \& E. Weber's Verlag, Berlin 30 - Alle Rechte, auch die des auszugsweisen Nachdruckes, der photomechanischen Wiedergabe, der Herstellung von Mikrofilmen und der Ubersetzung, vorbehalten. Archiv-Nr. 6600661 - Printed in Germany

Satz und Druds: Franz Spiller, Berlin 36 